\title{
sciendo

\section{Solar Facade Module for Nearly Zero Energy Building. Optimization Strategies}

\author{
Raivis SIRMELIS ${ }^{1 *}$, Ruta VANAGA ${ }^{2}$, Ritvars FREIMANIS ${ }^{3}$, Andra BLUMBERGA $^{4}$ \\ ${ }^{1-4}$ Institute of Energy Systems and Environment, Riga Technical University, \\ Azenes iela 12/1, Riga, LV-1048, Latvia
}

\begin{abstract}
The study presented in this paper is a continuation of small-scale passive solar wall module testing to evaluate: 1) the impact of phase change material embedded in building envelope on indoor air temperature in comparison to reference wall insulated with mineral wool 2) the impact of Fresnel lens on heat transfer processes in designed module compared to PMMA acrylic glass. Six different solar wall modules and a reference wall module were built and tested in a laboratory under controlled conditions. Compared to previous studies, changes in the experimental setup were made - solar radiation intensified, simulated outdoor temperature adjusted. The study shows explicitly the phase change melting processes in different modules tested, describing the differences between modules and impact of Fresnel lenses and insulation solutions. Room temperature with solar wall modules after the full cycle of charging and discharging latent and sensible energy $(24 \mathrm{~h})$ is higher than in the reference wall. Two of 3 of the proposed solar wall modules with Fresnel lens are more effective than modules with PMMA.
\end{abstract}

Keywords - Fresnel lens; PCM; solar wall

\begin{tabular}{|lll}
\hline Nomenclature & & \\
PCM & Phase change material & PCM \\
GHG & Greenhouse gases & GHG \\
NZEB & Nearly zero energy building & NZEB \\
PMMA & Poly(methyl methacrylate) & PMMA \\
\hline
\end{tabular}

\section{INTRODUCTION}

Buildings and construction account for $40 \%$ of primary energy and related GHG emissions in most countries according to International Energy Agency (IEA) reports [1]. To achieve EU GHG emission reduction plans, Directive 2010/31/EU [2] targets the building energy efficiency declaring that by the end of 2020 all new buildings have to be nearly zero energy buildings (NZEB). NZEB is a building of very high energy performance and the energy needed is produced by renewable energy sources preferably on site or nearby. The ideas of low, nearly zero and plus energy buildings have been developed over the last decades [3]-[11]. Renewable energy production on-site carries unstable character - it is not constantly available be it solar or wind power. Therefore one of the challenges of NZEB and plus energy buildings is energy storage. There are several strategies discussed for application in buildings

\footnotetext{
${ }^{*}$ Corresponding author.

E-mail address: raivis.sirmelis@gmail.com 
- thermal energy storage, pumped hydro energy storage, battery energy storage and thermochemical energy storage [12]-[20]. Energy can be stored daily shifting the peak loads and seasonally accumulating generated surplus energy. Energy can be stored on the consumer level and as a part of the district heating system [21]. This study focuses on the energy accumulation in phase change material on a daily time scale at the consumer level.

PCM materials in buildings can be used passively with no auxiliary energy demand or actively in systems that need auxiliary energy. In passive systems, phase change materials are embedded in building materials - walls, floors, ceilings, windows, tiles and boards [22]. It might be filled in containers and built-in building construction [23]-[25] or in the form of capsules embedded in the material itself; be it concrete or light concrete wall [26], [27] or insulation layer [28]-[30] and even in movable designs [31]. In active systems, phase change materials are installed in engineering systems as heat exchangers in HVAC and hot water systems. Auxiliary energy is needed in such systems to move the energy carrier around [32], [33]. In the presented research, PCM volume is incorporated in a wall structure with no auxiliary energy provided. It acts by passively absorbing and releasing solar energy.

Phase change materials have low thermal conductivity. In order to optimize energy storage, different heat transfer enhancers can be used in solar energy storage systems containing PCM - carbon additives, metal and metal foams in different geometries [34]-[36]. Another strategy of enhancing the heat transfer is the use of solar concentrators. Fresnel lens has been widely explored and recognized as effective for focusing solar energy. Several studies have been carried out and achieved the temperatures from 60 to $2000{ }^{\circ} \mathrm{C}$, which proves their benefits in solar beam creation [37], [38]. In the proposed solar wall module, heat transfer enhancers and a Fresnel lense are installed.

The aim of the study presented in the paper is to explore the heat transfer processes in small-scale passive solar wall modules containing phase change material, copper heat transfer enhancers and a Fresnel lens solar concentrator. Tests are done to evaluate:

1. Influence of PCM embedded in wall construction on indoor temperature in comparison to the reference wall where rock wool is used for insulation;

2. Influence of Fresnel lens on heat transfer processes in wall modules in comparis on to PMMA acrylic glass.

\section{EXPERIMENTAL SETUP}

\subsection{Background of Experimental Study}

This study is a continuation of passive solar wall research [39], [40]. Compared to previous studies, changes in experimental setup were made - solar radiation intensified, simulated outdoor temperature adjusted.

Six small scale passive solar wall modules were built at a scale of $1: 1$ and tested in a laboratory.

Each module consists of two parts - PCM container $(127 \cdot 127 \cdot 60 \mathrm{~mm})$ supplemented with heat transfer enhancers and heat transfer unit $(127 \cdot 127 \cdot 71 \mathrm{~mm})$ (Fig.1). 


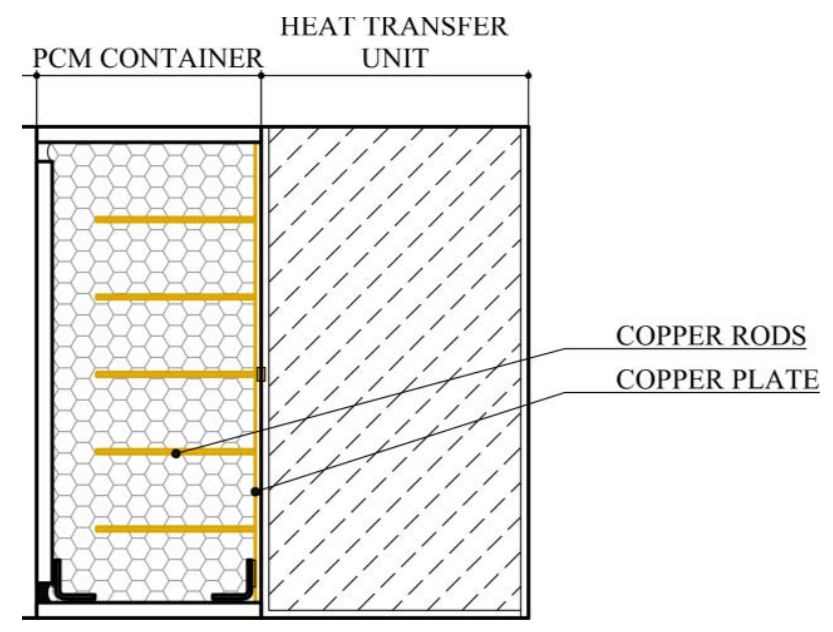

Fig. 1. Module scheme.

To optimize heat exchange in the module, three alternatives for the heat transfer unit are studied - still air, aerogel filling, and insulated cone. To evaluate the impact of the solar concentrator, all three alternatives are tested in two regimes - with Fresnel lens and with acrylic glass. There are two kinds of wall modules - in 3 modules (cone, aerogel, air space) Fresnel lens as for solar radiation concentration is installed, in other 3 modules (cone, aerogel, air space) translucent PMMA acrylic glass is installed to transmit solar radiation. For solar energy concentration, the Fresnel lens $127 \cdot 127 \mathrm{~mm}$, focal length $71 \mathrm{~mm}$ [41] is used. To compare the solar module with a conventional building envelope, the reference module is built containing mineral wool (Fig. 2).

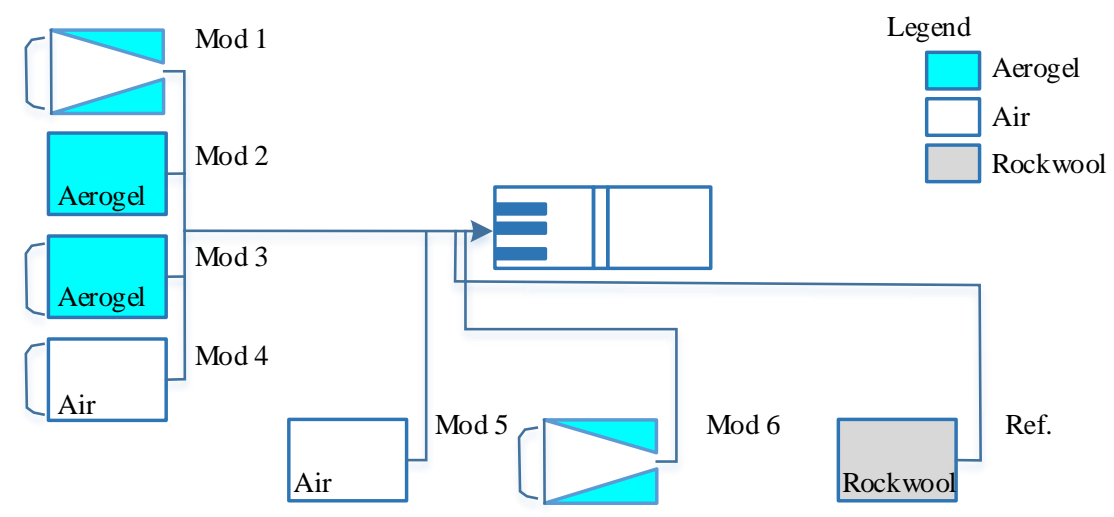

Fig. 2. Solar wall module constructions.

Paraffin RT21HC (Rubitherm) is used in the experiment as the phase change material (see Table 1 for technical data). 
TABle 1. Properties of PARAFFin RT21HC [42]

\begin{tabular}{ll}
\hline Melting temperature & $20-23^{\circ} \mathrm{C}$ \\
Solidification temperature & $21-19^{\circ} \mathrm{C}$ \\
Heat conductivity & $0.2 \mathrm{~W} /(\mathrm{m} \cdot \mathrm{K})$ \\
Heat storage capacity & $190 \mathrm{~kJ} / \mathrm{kg}$ \\
\hline
\end{tabular}

All modules were inserted in a test box $(557 \cdot 557 \cdot 600 \mathrm{~mm})$ (Fig. 3). The outer walls of the box are made of $15 \mathrm{~mm}$ thick plywood. From the inside, the plywood walls are covered with 200 to $300 \mathrm{~mm}$ thick mineral wool. In the middle of a test box there is an "indoor space" $140 \cdot 140 \cdot 127 \mathrm{~mm}$. The experimental setup is built in a refrigeration chamber to maintain constant "outside temperature".

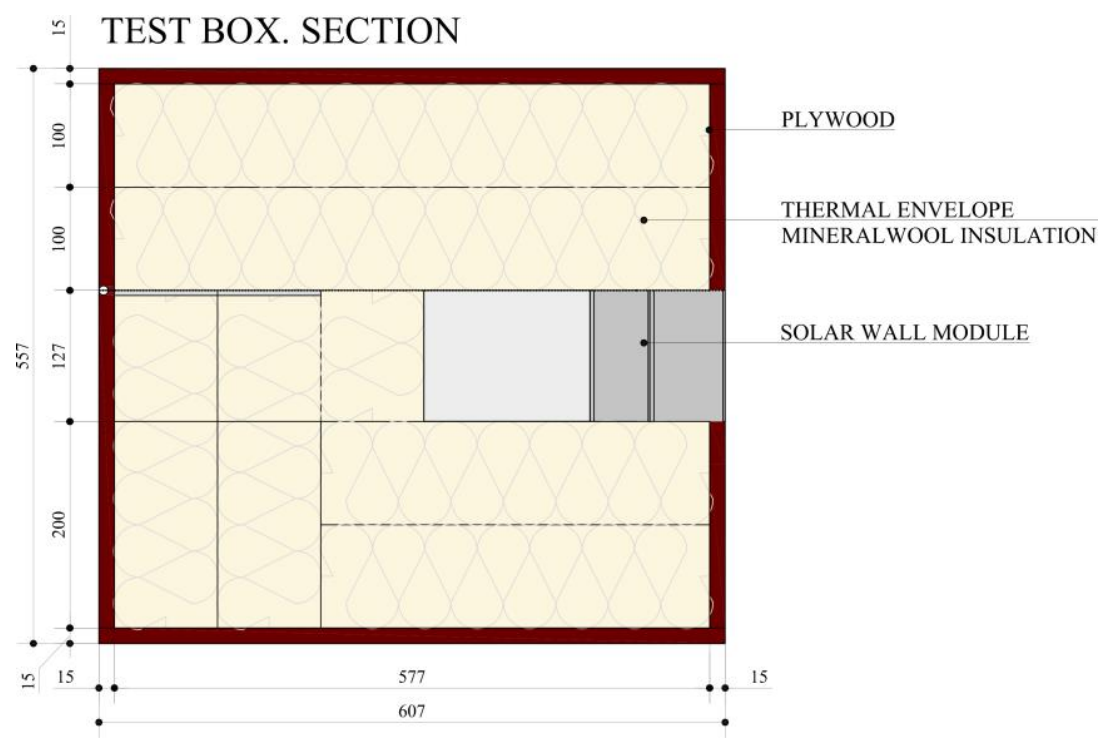

Fig. 3. Solar module in a test box.

For solar radiation simulation, a special lamp GE SUPER CP60 EXC VNS 230V | $1000 \mathrm{~W}$ G16d 3200K | General Electric was used and controlled with a dimmer UNI BAR Elation professional. The wall modules were exposed to solar radiation of $1000 \mathrm{~W} / \mathrm{m}^{2}$ during heating phase.

The distance between the solar radiation simulation lamp and test box is $2329 \mathrm{~mm}$ (Fig. 4). The experiment imitates one hypothetical day in spring with solar radiation available for 6 hours 39 minutes (outdoor temperature $+15^{\circ} \mathrm{C}$ ). For the rest, 17 hours 21 minute $+10^{\circ} \mathrm{C}$ are maintained in refrigeration chamber. 

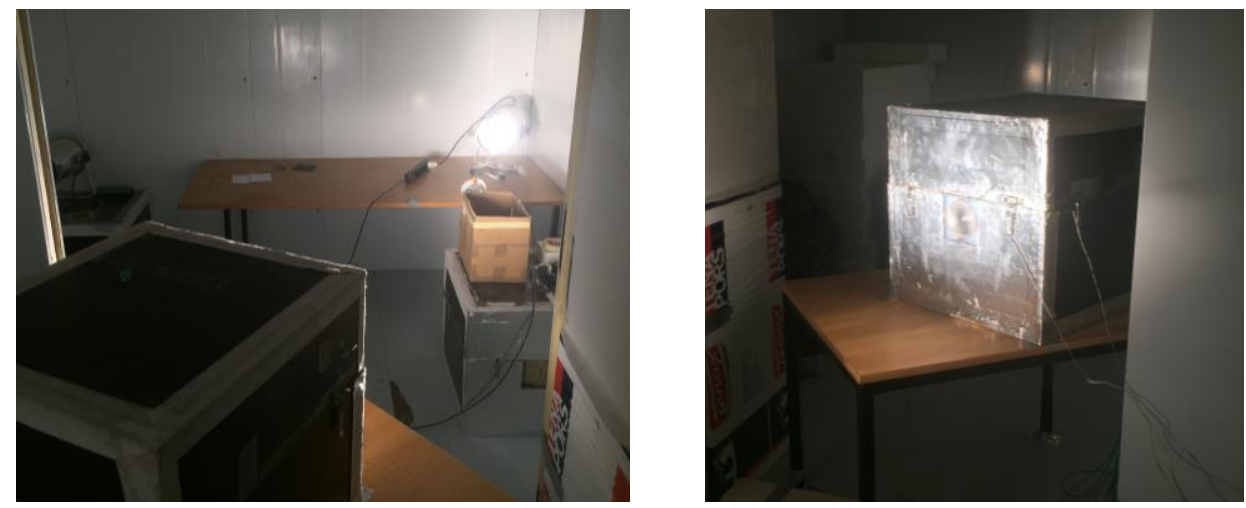

Fig. 4. Experimental setup.

\subsection{Instrumentation Used}

Parameters during the experiment are registered by Multipurpose data logger CR1000| Campbell Scientific combined with multiplexer AM16/32 | Campbell Scientific. Data are read every 60 seconds. Solar radiation is measured by pyranometer CMP3 | Kipp \& Zonen. Type $\mathrm{K}$ thermocouples are used to measure temperature.

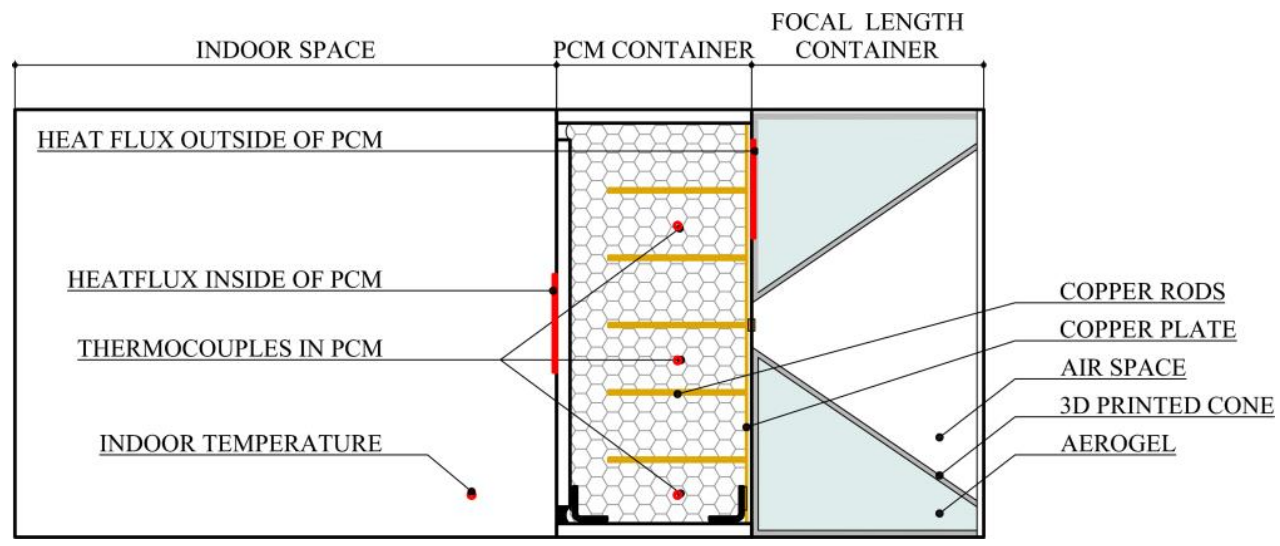

Fig. 5. Monitoring equipment scheme.

There were 5 thermocouples used to collect the temperature data during the experiments (Fig. 5). Three thermocouples were placed in a PCM container close to the back wall to observe the heating process in different layers - lower, middle and upper layer. The fourth thermocouple was placed to log indoor space temperature. The fifth thermocouple was placed outside the box at the wall of refrigeration camera to log the "ambient" temperature.

Two meters Sequoia SHF were used to collect heat flow data and placed on the outside and inside walls of the PCM container (Fig. 4). Heat flow meters will provide addition information on the heat transfer processes in the solar wall module. 


\section{Results}

\subsection{Process of Experiment}

In one experimental cycle $(24 \mathrm{~h})$ charging and discharging of PCM takes place. The duration of the charging phase is $6 \mathrm{~h} 39$ minutes, constant solar simulation $1000 \mathrm{~W} / \mathrm{m}^{2}$ and ambient temperature of $15^{\circ} \mathrm{C}$. The duration of discharging phase was $17 \mathrm{~h} 21$ minutes at an ambient temperature of $10^{\circ} \mathrm{C}$.

\subsection{Heating and Cooling Temperatures of PCM}

Collected data show that heating of PCM happens gradually layer-by-layer in from the upper to lower level. Fig. 6 shows the melting process in Setup 4 (Fresnel lens and air). At the beginning, all three temperatures follow on one linear path. At $17^{\circ} \mathrm{C}$, the process slows down and the graph curves - the phase change is starting to take place in some parts of the PCM. From 17-27 ${ }^{\circ} \mathrm{C}$ temperatures differentiate in layers - it shows that PCM melts in fractions. After the melting process (latent heat phase), a fraction of the PCM starts accumulating sensible heat and temperatures rise again. Parts in the graph with steep increase of temperature reflect changing to sensible heat in fractions of PCM. The upper layer (temp 3 ) is the first to overcome phase change. At $28{ }^{\circ} \mathrm{C}$, liquid PCM stratifies (there is $1{ }^{\circ} \mathrm{C}$ temperature difference between each layer) and linearly rises. After the solar radiation simulator is switched off, temperatures decrease almost linearly until solidification starts at $23{ }^{\circ} \mathrm{C}$.

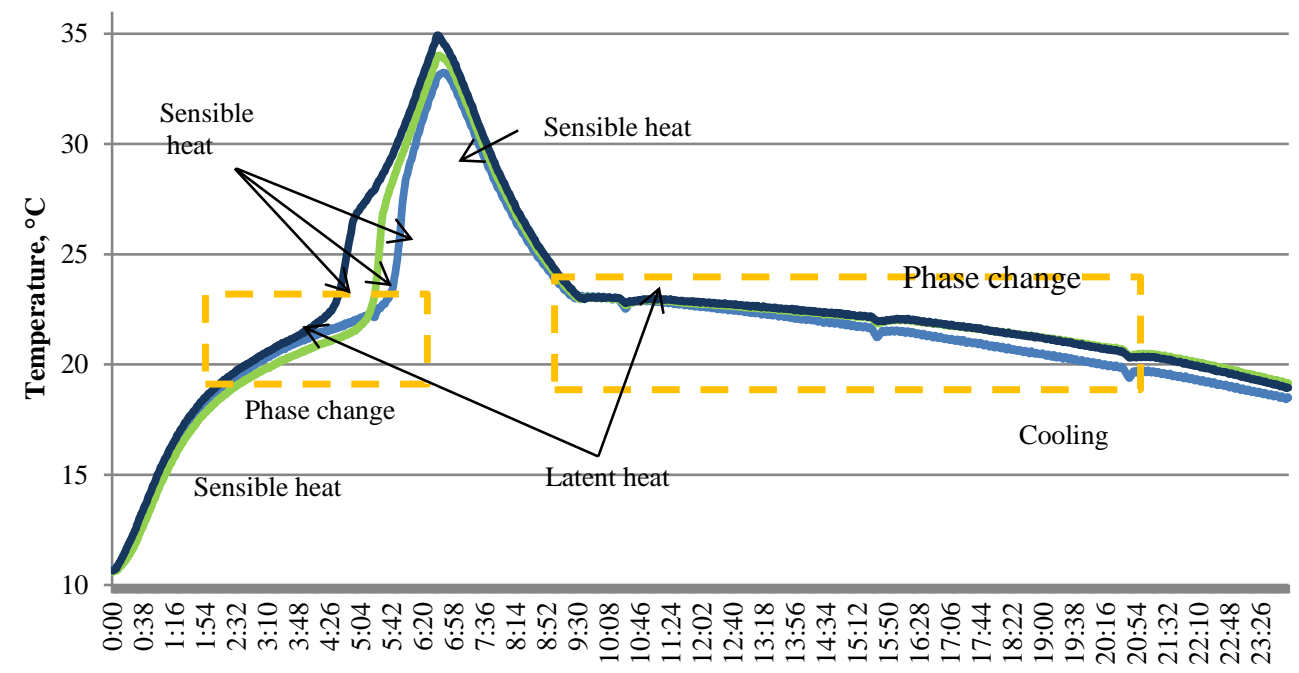

\section{Hours}

$\longrightarrow$ Temp PCM(1) $\longrightarrow$ Temp PCM(2) $\longrightarrow$ Temp PCM(3)

Fig. 6. Melting process in SETUP 4.

The melting process in all setups is similar to the described process in Setup 4. Setup 4 was chosen as an example, because it is one of two setups where PCM melted completely.

Fig. 7 shows the average temperatures in PCM of all setups. The red dashed line marks the time at which the solar radiation simulator was switched off. 
In Setup 4 (Fresnel lens and air) and Setup 5 (PMMA and air), all the PCM volume underwent a melting phase. Bumps in the graphs reflect the melting in layers $-1^{\text {st }}$ bump coincides with upper layer, $2^{\text {nd }}$ bump with middle layer, but $3^{\text {rd }}$ bump with bottom layer entering sensible heat phase. The temperature of PCM starts to increase rapidly after 4:30 when the average temperature is around $22{ }^{\circ} \mathrm{C}$ in Setup 4 and Setup 5. The second wave of temperature increase is after $5 \mathrm{~h} 00$ at average temperature of $28^{\circ} \mathrm{C}$ but melting of the bottom layer is less visible on graph Fig. 6 at 6:00.

In other graphs there are no three bumps - in other setups PCM was not melted completely.

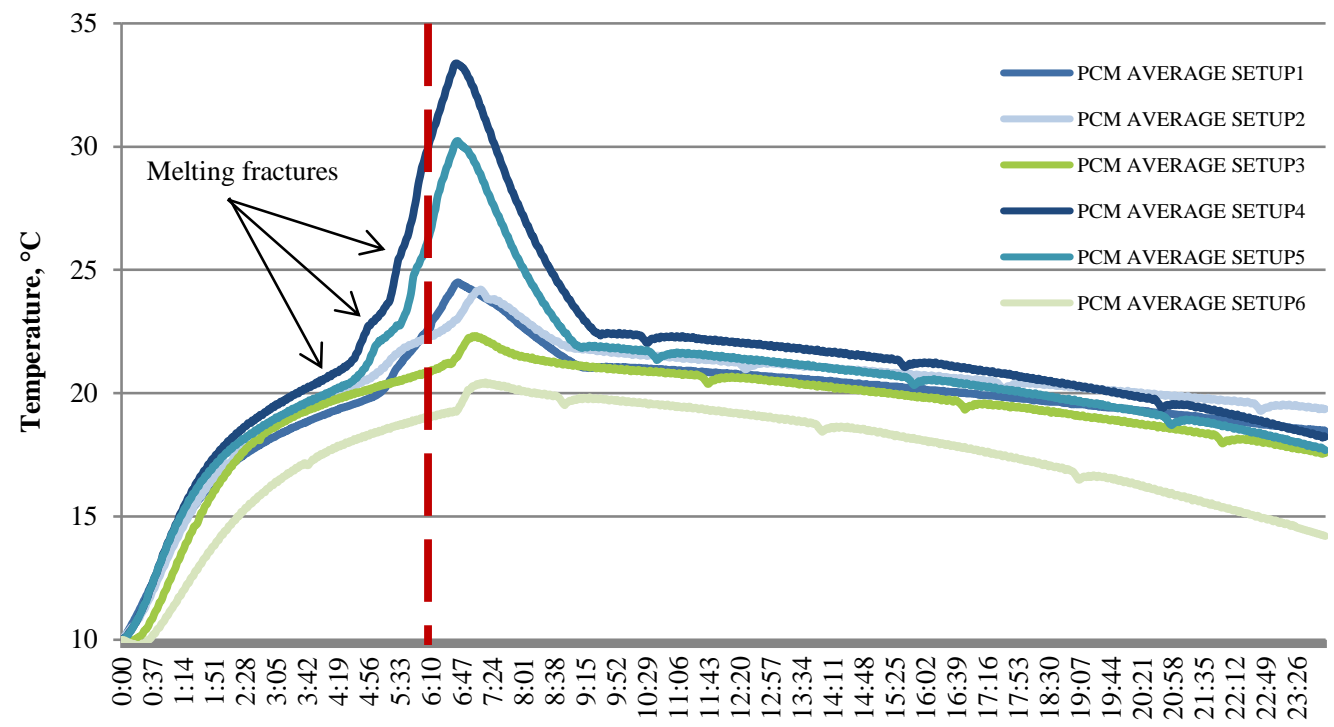

Hours

Fig. 7. PCM average temperature.

In Setups 1, 4 and 5, PCM starts to cool right after the solar radiation is switched off, but in other setups, the temperature rises for about 20 minutes and then starts to cool. That is related to the un-melted fraction in PCM - if all PCM is melted, cooling starts right away; if there are un-melted fractions left when the solar radiation simulator is switched off, PCM is able to absorb the heat from warmed copper plate and temperature rises.

Fig. 7 graphs allow to conclude, in which setup PCM temperature was the highest at the charging phase and in which setup PCM temperature is the lowest after discharging phase. The highest average temperature in PCM $33.38^{\circ} \mathrm{C}$ was reached in Setup 4 (Fresnel lens + air) after 6 hours 40 minutes. The next highest average temperature of $30.23{ }^{\circ} \mathrm{C}$ was reached in Setup 5 (PMMA glass + air) after 6 hours 41 minutes. The next two to follow with great distance are Setup 1 (Fresnel lens + cone and aerogel) and Setup 2 (PMMA glass + aerogel) with close highest average temperatures of $24.5^{\circ} \mathrm{C}$ and $24.21{ }^{\circ} \mathrm{C}$, respectively. Setup 3 (Fresnel lens + aerogel) and Setup6 (PMMA glass + cone and aerogel) are charging the slowest and reaching the highest average temperature $22.32{ }^{\circ} \mathrm{C}$ and $20.44{ }^{\circ} \mathrm{C}$, respectively. Less insulated modules are charging faster than better insulated modules.

In the discharging phase, the scene is different. The temperature range is much narrower, and the leaders changed. The highest temperature after discharging is found in Setup 2 
$19.35{ }^{\circ} \mathrm{C}$ followed by Setup 1 at $18.47^{\circ} \mathrm{C}$. The well-insulated setups have outperformed charging phase leaders Setup 4 and Setup 5 at $18.24^{\circ} \mathrm{C}$ and $17.69^{\circ} \mathrm{C}$, respectively. The lowest temperatures after full cycle of charging and discharging are found in setups that had the least temperatures in the charging phase - i.e. Setup 3 and Setup 6 with $17.57^{\circ} \mathrm{C}$ and $14.21{ }^{\circ} \mathrm{C}$, respectively. Table 2 shows the highest average temperatures at the charging phase and lowest average temperatures after the discharging phase in PCM in all setups.

TABle 2. HigheSt AND LOWEST AVERAgE TEMPERATURES OF PCM

\begin{tabular}{llll}
\hline Setup 1 (Fresnel lens, cone and aerogel) & Time & Max $T,{ }^{\circ} \mathrm{C}$ & Min T, ${ }^{\circ} \mathrm{C}$ \\
\hline Setup 2 (PMMA glass and aerogel) & $07: 25$ & 24.50 & 18.47 \\
\hline Setup 3 (Fresnel lens and aerogel) & $07: 04$ & 22.32 & 19.35 \\
\hline Setup 4 (Fresnel lens and air) & $06: 40$ & 33.38 & 17.57 \\
\hline Setup 5 (PMMA glass and air) & $06: 41$ & 30.23 & 18.24 \\
\hline Setup 6 (PMMA glass, cone and aerogel) & $07: 09$ & 20.44 & 14.69 \\
\hline
\end{tabular}

\subsection{Room Temperature}

Fig. 8 shows temperatures in indoor space of all setups including the reference wall. The red dashed line marks the time at which the solar radiation simulator was switched off. Setups 4 and 5 which gained the highest temperature in PCM at the charging phase show similar tendencies in room temperature reaching highest temperatures at $26.48{ }^{\circ} \mathrm{C}$ and $24.08{ }^{\circ} \mathrm{C}$. Ranking third are three setups - Setups 1,2 and 3 all reaching $21.5^{\circ} \mathrm{C}$ of indoor space temperature. In Setup 6 , the maximum indoor temperature is much lower, just $19.62{ }^{\circ} \mathrm{C}$.

Unlike the the temperature in PCM, indoor space temperature in all setups continues to rise after the solar radiation simulator is switched off, indicating that thermal energy from the building envelope is transferred to the indoor space.

At the discharge phase, a change of leaders can be observed. There are four close measurements after $24 \mathrm{~h}$, all within a range of measurement error $\pm 0.5^{\circ} \mathrm{C}\left(16.57-16.2^{\circ} \mathrm{C}\right)$. Ranking from the highest - Setup 1, Setup 4, Setup 2, Setup 3. One degree lower is the Setup 5 at $15.53{ }^{\circ} \mathrm{C}$. The lowest temperature after $24 \mathrm{~h}$ cycle is found to be in Setup 6 at $13.53{ }^{\circ} \mathrm{C}$.

The indoor temperature in the reference wall reaches $20.31{ }^{\circ} \mathrm{C}$ exposed to solar radiation. In the reference wall the temperature also rises after solar radiation is switched off due to the heat capacity of the thermal envelope. After $24 \mathrm{~h}$ cycle, the indoor temperature decreased to $10.56{ }^{\circ} \mathrm{C}$. The effect of phase change material on indoor temperature is expressed in the temperature difference after a $24 \mathrm{~h}$ cycle and it is $3-6{ }^{\circ} \mathrm{C}$ compared to modules with integrated PCM.

Another task in this study was to evaluate the difference between setups with Fresnel lens and without. Fig. 9 illustrates the impact of Fresnel lens on PCM average temperature. In the setups with airspace and cone + aerogel Fresnel lens, setups show higher reached temperature both at the charging peak and after a 24 cycle. In setups with aerogel, Setup 2 with PMMA shows a higher reached temperature both at the peak temperature and after $24 \mathrm{~h}$. 


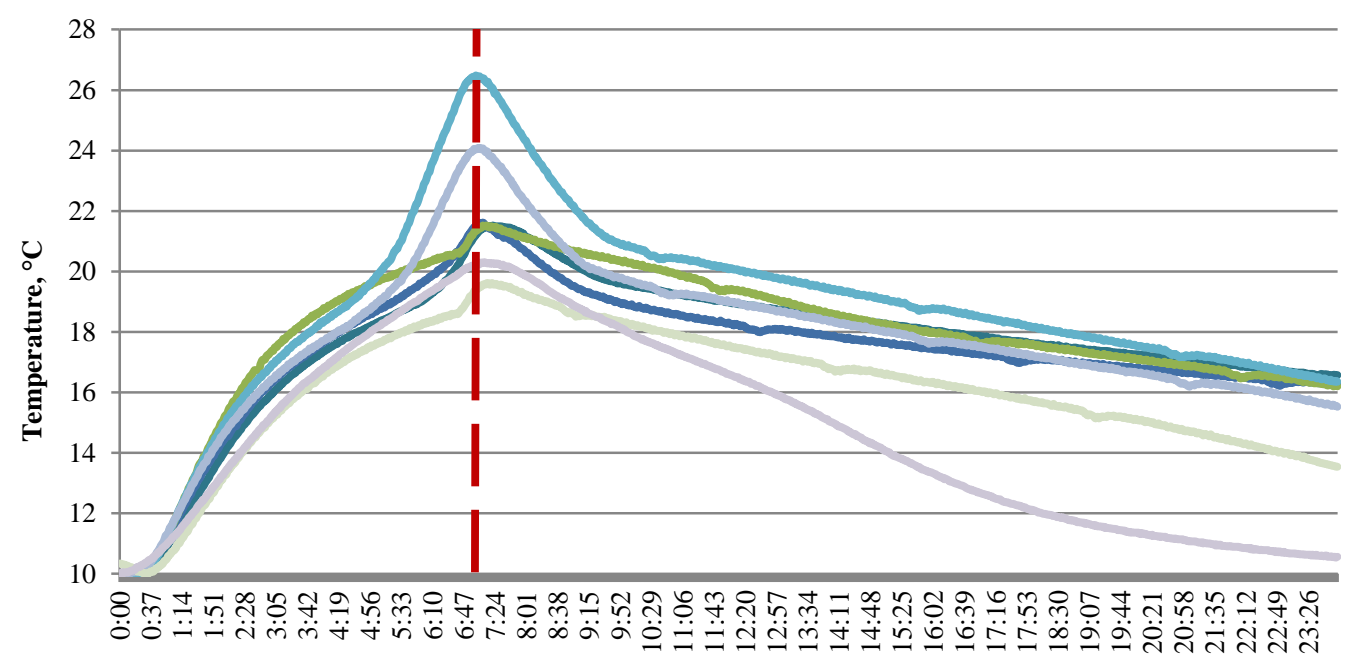

Hours

\begin{tabular}{lll}
\hline Indoor SETUP1 & Indoor SETUP2 & Indoor SETUP3 SETUP4 \\
Indoor SETUP5 & Indoor SETUP6 & Indoor REF_WALL
\end{tabular}

Fig. 8. Room temperatures in all setups.

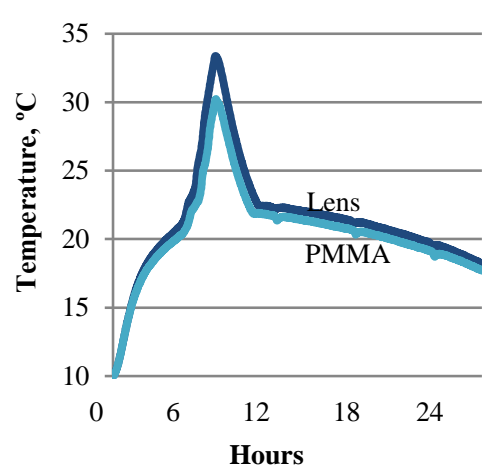

(a)

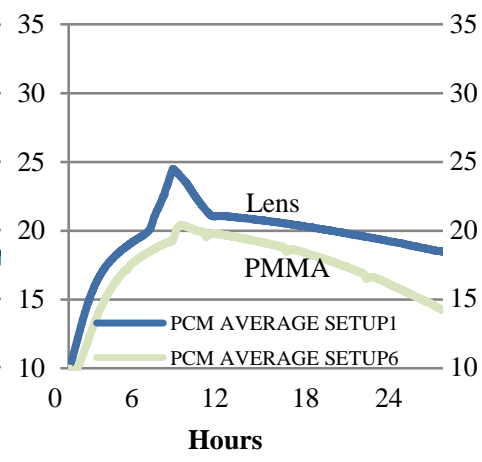

(b)

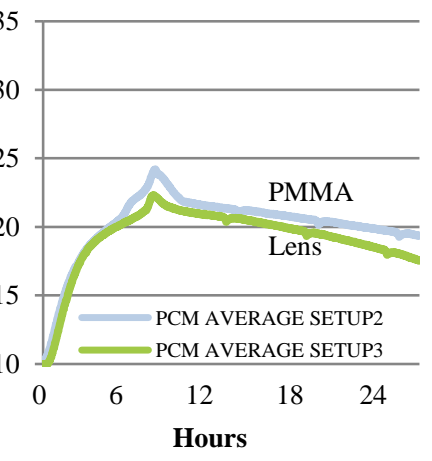

(c)

Fig. 9. Fresnel lens vs PMMA glass - average temperature in PCM: (a) air space; (b) cone + aerogel, (c) aerogel.

Fig. 10 illustrates Fresnel lens impact on indoor temperature. Here, similarly to the setups with airspace and cone + aerogel, Fresnel lens setups show higher reached temperature both at the peak and after a $24 \mathrm{~h}$ cycle. But in setups with aerogel both room temperature at the peak and after a $24 \mathrm{~h}$ cycle are almost the same. Setup 2 shows a slightly higher result of $0.1{ }^{\circ} \mathrm{C}$ at peak and $0.06{ }^{\circ} \mathrm{C}$ higher after $24 \mathrm{~h}$. But the Fresnel lens setup graph line is steeper than the PMMA graph line, indicating that after some more hours, the indoor temperature in the PMMA setup would be higher than in the Fresnel lens setup. The discharging process in aerogel setups differs from the other 4 setups. In other setups, the tendencies in graphs are quite similar. But in aerogel setups indoor temperature comparison graph shows that at the 
beginning of the discharging phase, indoor temperature in Setup 2 with PMMA decreases more rapidly and nslows down, but indoor temperature in Setup 3 decreases evenly.
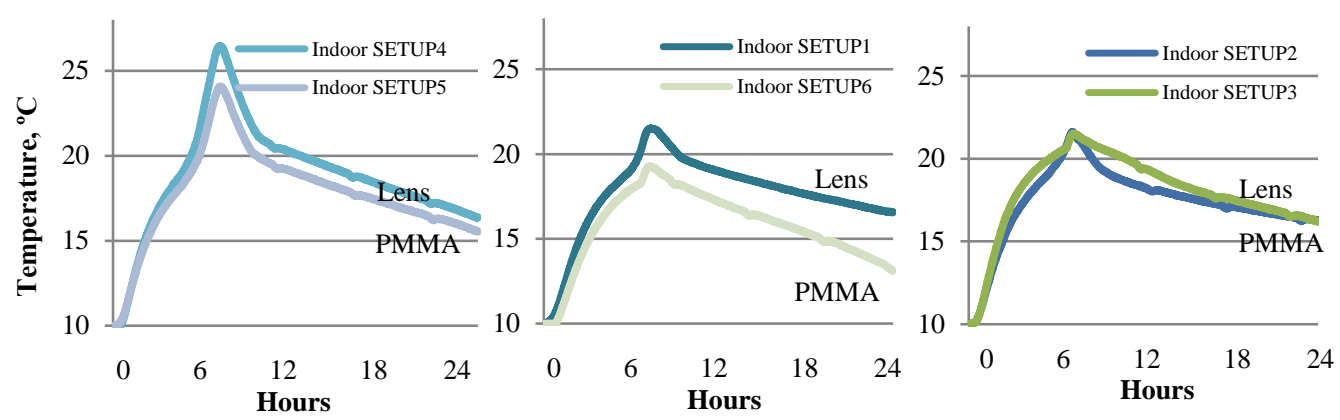

Fig. 10. Fresnel lens vs PMMA glass - indoor temperature.

\section{Discussion}

The paper presents results of the impact of phase change material embedded in the thermal envelope on indoor temperature in the heating season. An experimental study of passive solar wall modules containing PCM provides several findings:

- Data collected show that in all setups with PCM indoor temperature after $24 \mathrm{~h}$ was higher than in the reference wall setup - it indicates that the proposed passive solar wall prototype has accumulated solar energy and transferred it to the inside space and therefore the thermal envelope with embedded phase change materials can become an active part of the building energy balance absorbing and releasing energy on a daily time scale;

- There are significant differences at peak indoor temperatures but at the end of the cycle of $24 \mathrm{~h}$ indoor temperatures of 5 setups meets in the solidification phase within a range of $0.5^{\circ} \mathrm{C}$. Modules that provide higher heat gains in the charging phase are exposed to higher heat losses at the discharge phase. To identify more significant temperature differences cycle of 48 hours should be carried out;

- In setups with air space and cone, passive solar wall modules with Fresnel lens are more effective than the same modules with PMMA. Temperature in PCM and indoor space after a 24-hour cycle is higher in modules with lenses. In setups with aerogel, the module with PMMA is slightly more effective than the Fresnel lens setup temperature in PCM is $\sim 2{ }^{\circ} \mathrm{C}$ higher in setup with PMMA glass, but the temperature difference after $24 \mathrm{~h}$ cycle in indoor space is almost the same in both setups. This proves the effect of solar energy concentration component in designed solar wall;

- The highest indoor temperature after 24 hours is reached in Setup 1 with cone and Fresnel lens. This setup provides average heat gains in the charging phase compared to other setups, but ensures minimal heat losses to outdoors. Efficiency of this setup could be improved by enhancing heat transfer during the charging phase.

Tests carried out during the study show strength and weaknesses of different solar module designs and may serve as a guide for solar walls with embedded phase change materials. 


\section{Conclusions}

In further research passive solar wall modules will be improved 1) optimizing the metal fraction in PCM while preserving the same heat transfer level and 2) the contact surface of the plate needs to be minimised in order to reduce heat losses to the outside during the night. Additional issue for further research is to evaluate the impact on indoor temperature of the proposed passive solar wall module in the cooling season.

\section{ACKNOWLEDGEMENT}

This research is funded by the Ministry of Economics of the Republic of Latvia, project "Improvement of building energy efficiency technologies", project No. VPP-EM-EE-2018/1-0003.

\section{REFERENCES}

[1] IEA. Policy Pathways Brief: Modernising Building Energy Codes 2017. International Energy Agency, 2017.

[2] Directive 2010/31/EU of the European Parliament and of the Council of 19 May 2010 on the energy performance of buildings. Official Journal of the European Union 2010:L153/13.

[3] Lydona G. P., et al. Coupling energy systems with lightweight structures for a net plus energy building. Applied Energy 2017:189:310-326. doi:10.1016/j.apenergy.2016.11.110

[4] Passer A., et al. The impact of future scenarios on building refurbishment strategies towards plus energy buildings. Energy and Buildings 2016:124:153-163. doi:10.1016/j.enbuild.2016.04.008

[5] Risholt B., Time B., Hestnes A. G. Sustainability assessment of nearly zero energy renovation of dwellings based on energy, economy and home quality indicators. Energy and Buildings 2013:60:217-224. doi:10.1016/j.enbuild.2012.12.017

[6] Wiberg A. H., et al. A net zero emission concept analysis of a single-family house. Energy and Buildings 2014:74:101110. doi:10.1016/j.enbuild.2014.01.037

[7] Attia S., et al. Overview and future challenges of nearly zero energy buildings (NZEB) design in Southern Europe. Energy and Buildings 2017:155:439-458. doi:10.1016/j.enbuild.2017.09.043

[8] Chastas P., et al. Embodied Energy and Nearly Zero Energy Buildings: A Review in Residential Buildings. Procedia Environmental Sciences 2107:38:554-561. doi:10.1016/j.proenv.2017.03.123

[9] Weißenberger M., Jensch W., Lang W. The convergence of life cycle assessment and nearly zero-energy buildings: The case of Germany. Energy and Buildings 2014:76:551-557. doi:10.1016/j.enbuild.2014.03.028

[10] Schimschar S., Blok K., Boermans T., Hermelink A. Germany's path towards nearly zero-energy buildings - Enabling the greenhouse gas mitigation potential in the building stock. Energy Policy 2011:39(6):3346-3360. doi:10.1016/j.enpol.2011.03.029

[11] Albatayneh A., Alterman D., Page A., Moghtaderi B. The Significance of Building Design for the Climate. Environmental and Climate Technologies 2018:22(1):165-178. doi:10.2478/rtuect-2018-0011

[12] Bot K., et al. Energy performance of buildings with on-site energy generation and storage - An integrated assessment using dynamic simulation. Journal of Building Engineering 2019:24:100769. doi:10.1016/j.jobe.2019.100769

[13] Kuznik F., et al. A review on recent developments in physisorption thermal energy storage for building applications. Renewable and Sustainable Energy Reviews 2018:94:576-586. doi:10.1016/j.rser.2018.06.038

[14] Liu J., Chen X., Cao S., Yang H. Overview on hybrid solar photovoltaic-electrical energy storage technologies for power supply to buildings. Energy Conversion and Management 2019:187:103-121. doi:10.1016/j.enconman.2019.02.080

[15] Silva G. O., Hendrick P. Pumped hydro energy storage in buildings. Applied Energy 2016:179:1242-1250. doi:10.1016/j.apenergy.2016.07.046

[16] Pero C., et al. Energy storage key performance indicators for building application. Sustainable Cities and Society 2018:40:54-65. doi:10.1016/j.scs.2018.01.052

[17] Niu J., Tian Z., Lu Y., Zhao H. Flexible dispatch of a building energy system using building thermal storage and battery energy storage. Applied Energy 2019:243:274-287. doi:10.1016/j.apenergy.2019.03.187

[18] Krese G., Koželj R., Butala V., Stritih U. Thermochemical seasonal solar energy storage for heating and cooling of buildings. Energy and Buildings 2018:164:239-253. doi:10.1016/j.enbuild.2017.12.057

[19] Li C., Yu H., Song Y., Liu Z. Novel hybrid microencapsulated phase change materials incorporated wallboard for year-long year energy storage in buildings. Energy Conversion and Management 2019:183:791-802. doi:10.1016/j.enconman.2019.01.036 
[20] Dzikevics M., Ansone A., Veidenbergs I. Experimental Investigation of Flow Rate Impact on Thermal Accumulation System with PCM. Energy Procedia 2017:128:386-392. doi:10.1016/j.egypro.2017.09.043

[21] Schuchardt G. K. Integration of Decentralized Thermal Storages Within District Heating (DH) Networks. Environmental and Climate Technologies 2016:18(1):5-16. doi:10.1515/rtuect-2016-0009

[22] Kasaeian A., et al. Experimental studies on the applications of PCMs and nano-PCMs in buildings: A critical review. Energy and Buildings 2017:154:96-112. doi:10.1016/j.enbuild.2017.08.037

[23] Fateh A., et al. Numerical and experimental investigation of an insulation layer with phase change materials (PCMs). Energy and Buildings 2017:153:231-240. doi:10.1016/j.enbuild.2017.08.007

[24] Cascone Y., Capozzoli A., Perino M. Optimisation analysis of PCM-enhanced opaque building envelope components for the energy retrofitting of office buildings in Mediterranean climates. Applied Energy 2018:211:929-953. doi:10.1016/j.apenergy.2017.11.081

[25] Baetens R., Jellea B. P., Gustavsen A. Phase change materials for building applications: A state-of-the-art review. Energy and Buildings 2010:42(9):1361-1368. doi:10.1016/j.enbuild.2010.03.026

[26] Sukontasukkul P., et al. Thermal properties of lightweight concrete incorporating high contents of phase change materials. Construction and Building Materials 2019:207:431-439. doi:10.1016/j.conbuildmat.2019.02.152

[27] Ling T.-C., Poon C.-S. Use of phase change materials for thermal energy storage in concrete: An overview. Construction and Building Materials 2013:46:55-62. doi:10.1016/j.conbuildmat.2013.04.031

[28] Lee K. O., Medina M. A., Suna X., Jin X. Thermal performance of phase change materials (PCM)-enhanced cellulose insulation in passive solar residential building walls. Solar Energy 2018:163:113-121. doi:10.1016/j.solener.2018.01.086

[29] Kośny J., et al. Thermal load mitigation and passive cooling in residential attics containing PCM-enhanced insulations. Solar Energy 2014:108:164-177. doi:10.1016/j.solener.2014.05.007

[30] Boussaba L., Foufa A., Makhlouf S., Lefebvre G., Royon L. Elaboration and properties of a composite bio-based PCM for an application in building envelopes. Construction and Building Materials 2018:185:156-165. doi:10.1016/j.conbuildmat.2018.07.098

[31] Gracia A. Dynamic building envelope with PCM for cooling purposes - Proof of concept. Applied Energy 2019:235:1245-1253. doi:10.1016/j.apenergy.2018.11.061

[32] Raja V. A. A., Velraj R. Review on free cooling of buildings using phase change materials. Renewable and Sustainable Energy Reviews 2010:14(1):2819-2828. doi:10.1016/j.rser.2010.07.004

[33] Osterman E., et al. Review of PCM based cooling technologies for buildings. Energy and Buildings 2012:49:37-49. doi:10.1016/j.enbuild.2012.03.022

[34] Al-Maghalseh M., Mahkamov K. Methods of heat transfer intensification in PCM thermal storage systems: Review paper. Renewable and Sustainable Energy Reviews 2018:92:62-94. doi:10.1016/j.rser.2018.04.064

[35] Choi D. H., Lee J., Hong H., Kang Y. T. Thermal conductivity and heat transfer performance enhancement of phase change materials (PCM) containing carbon additives for heat storage application. International Journal of Refrigeration 2014:42:112-120. doi:10.1016/j.ijrefrig.2014.02.004

[36] Fan L., Khodadadi J. M. Thermal conductivity enhancement of phase change materials for thermal energy storage: A review. Renewable and Sustainable Energy Reviews 2011:15(1):24-46. doi:10.1016/j.rser.2010.08.007

[37] Pigueiras E. L., Luque A. Fresnel lens analysis for solar energy applications. Applied Optics 1981:20(17):2941-2945. doi:10.1364/AO.20.002941

[38] Xie W. T., Dai Y. J., Wang R. Z., Sumathy K. Concentrated solar energy applications using Fresnel lenses: A review. Renewable and Sustainable Energy Reviews 2011:15(6):2588-2606. doi:10.1016/j.rser.2011.03.031

[39] Vanaga R., et al. Solar facade module for nearly zero energy building. Energy 2018:157:1025-1034. doi:10.1016/j.energy.2018.04.167

[40] Mols T., et al. Experimental study of small-scale passive solar wall module with phase change material and Fresnel lens. Energy Procedia 2018:147:467-473. doi:10.1016/j.egypro.2018.07.048

[41] Edmund Optics [Online]. [Accessed 2.05.2019]. Available: https://www.edmundoptics.eu/p/5quot-x-5quot-4quot-focal-length-fresnel-lens/6959

[42] Rubitherm Technologies GmbH [Online]. [Accessed 13.05.2019]. Available: https://www.rubitherm.eu/media/products/datasheets/Techdata_-RT21HC_EN_06082018.PDF 